Ethiopian Journal of Environmental Studies \& Management 9(Suppl. 1): 815 - 828, 2016.

ISSN:1998-0507

doi: http://dx.doi.org/10.4314/ejesm.v9i1.2S

Submitted: May 03, 2016

Accepted: November 18, 2016

\title{
FLOOD RISK AND VULNERABILITY MAPPING OF SETTLEMENTS WITHIN UPPER AND LOWER NIGER RIVER BASIN, NIGERIA
}

\author{
ADEBAYO, H. OLUWASEGUN \\ Department of Geography, Olabisi Onabanjo University, Ago-Iwoye, Ogun State, Nigeria \\ Email: adebayooluwasegunhezekiah@gmail.com
}

\begin{abstract}
The frequency and intensity of flood disasters have become serious issues in the national development process of Nigeria as flood disasters have caused serious environmental damages, loss of human lives and other heavy economic losses. The starting point of concrete flood disaster mitigation efforts is to identify the areas with higher risk levels and fashion out appropriate preventive and response mechanisms. This research paper explored the potentials of Geographic Information System (GIS) in data capture, processing and analysis in identifying flood-prone areas for the purpose of planning for disaster mitigation and preparedness, using both upper and lower Niger River basin as units of analysis. This work uses a number of physical, demographic and landuse data which were obtained from Forestry Management Evaluation and Coordination Unit and were entered and use to develop a flood risk information system. Results were illustrated graphically and showed that generally, areas with height less than $180 \mathrm{~m}$ are categorized high risk areas; areas with height between 180.1 and 500m were categorized as medium or moderate risk areas while areas above $500 \mathrm{~m}$ are designated as low risk areas. At the end of the study, maps of flood vulnerable areas in the river basin was generated with a view to assisting decision makers on the menace posed by the disaster.
\end{abstract}

Key Words: Flood, Risk, Vulnerability, Geographical Information System (GIS), River Basin

\section{Introduction}

Floods have become a common natural disaster which has claimed many lives, displaced millions and resulted to the destruction of properties and degradation of contiguous farmlands. It is the most frequent and devastating natural disaster in the world (Adedeji, 2012). Indeed, the amount of economic damages affects a large proportion of people in low-lying coastal zones or other areas at risk of flooding and extreme weather condition. According to (Adedeji, 2012) flood is seen to have caused about half of disasters worldwide and $84 \%$ disaster deaths in the world. Primary cause of flooding in many parts of the world according to the Action Aid (2006) is directly or indirectly related to rainfall in the catchment areas of the major river systems. The unpredictability of rainfall in recent times has caused untold hardship during the raining season. However, flooding is not only related to 
heavy rainfall and extreme climatic events (Action Aid, 2006); it is also related to changes in the built up areas themselves. Urban areas such as Lagos, Port Harcourt, Kano, Ibadan, and Benin in Nigeria has always present some risk of flooding when rainfall occurs. Prevailing uncoordinated and uncontrolled urban growth allows for buildings or infrastructure to be constructed that actually obstruct natural drainage channels (Aina, 1995). It is very important to have sound and effective flood management and control measures because floods impose a curse on the society and proper management and control of its occurrence is of vital importance. This is only feasible if there are proper and effective flood hazard maps of the area for proper decision making (Adebayo, 2014). Flood hazard mapping is a vital component in flood mitigation measures; control and land use planning, and is also an important prerequisite for the flood insurance schemes in flood-prone areas (McCall, 2008). It creates easily-read, rapidlyaccessible charts and maps which facilitates the administrators and planners to identify areas of risk and prioritize their mitigation/ responseefforts.GIS applications in flood risk mapping range from storing and managing hydrological data to generating flood inundation and hazard maps to assist flood risk management.

Over the last decade in particular, a great deal of knowledge and experience has been gained in using GIS in flood risk mapping. There is need to utilize the opportunities facilitated by modern geospatial technology through the integration of satellite images with GIS for the production of such maps with high accuracy for the floodplain areas of Nigeria. There is an urgent need to include the concepts of disaster geoinformation management into emergency preparedness planning, spatial planning and environmental impact assessment. In developing countries like Nigeria, the advantages of flood risk-related spatial information within a GIS context have not been widely explored. There is a need to convert raw data into useful spatial information that allows the community and other actors to develop analytical processes for flood risk analysis and exploration of risk reduction alternatives.

The aim of this study is to identify flood- prone areas for the purpose of planning for disaster mitigation and preparedness, using Upper and Lower Niger river basin, Nigeria as a unit of analysis. The specific objectives of the study are as follows: 1) to identify the areas that are at risk of flooding using GIS techniques, 2) to identify and detail those factors that are relevant to current and future flood risks in the study area, $3)$ to examine the impact on and vulnerabilities of residents of selected poor urban communities in the study area to the increasing risk of floods, and 4) to outline policies to be applied to such areas to minimise and manage flood risk.

\section{Material and Methods Study Area}

The study area which covers the Upper and Lower Niger River Basin Development Authorities area (U\&LNRBDA) (Figure.1a\&1b) is located mainly between latitudes $7^{\circ}$ and $12^{\mathrm{O}} \mathrm{N}$ and between longitude $3^{\circ}$ and $9^{\circ} \mathrm{E}$ in Nigeria. The southern and western borders of the area are occupied by the Western Upland rising above 600 metres 
while the north and north east are occupied by North Central Plateau reaching about 1200 metres at its highest part. These highlands are separated by the Niger trough which is believed to be at one time an arm of the Atlantic Ocean in which older sedimentary rocks were deposited. The trough mainly consists of the Niger flood plain. The U\&LNRBDA area lies within the middle belt of Nigeria, a region of vulnerability with high seasonal and inter annual rainfall variability. The study area enjoys distinct wet and dry seasons. The wet and dry seasons are associated respectively with the prevalence of the moist maritime south-westerly monsoon from the Atlantic Ocean and the dry continental north -easterly wind from the Sahara desert. The annual rainfall varies between $1040 \mathrm{~mm}$ and $1260 \mathrm{~mm}$ over the region. The mean annual temperature is $27.4^{\circ} \mathrm{C}$ The area is drained by many rivers including Niger, Kaduna, Kotangora, Swashi, Kampe, Galma amongst others. The area is vegetated by forest savannah mosaic found on small pocket of land in the southern part where climate permits the growth of forest. Guinea savannah forms the main vegetation of the area except the Niger flood plain. The vegetation decreases in luxuriance northward in sympathy with rainfall amounts. A large percentage of the inhabitants are peasant farmers and rain- fed agriculture is very important.

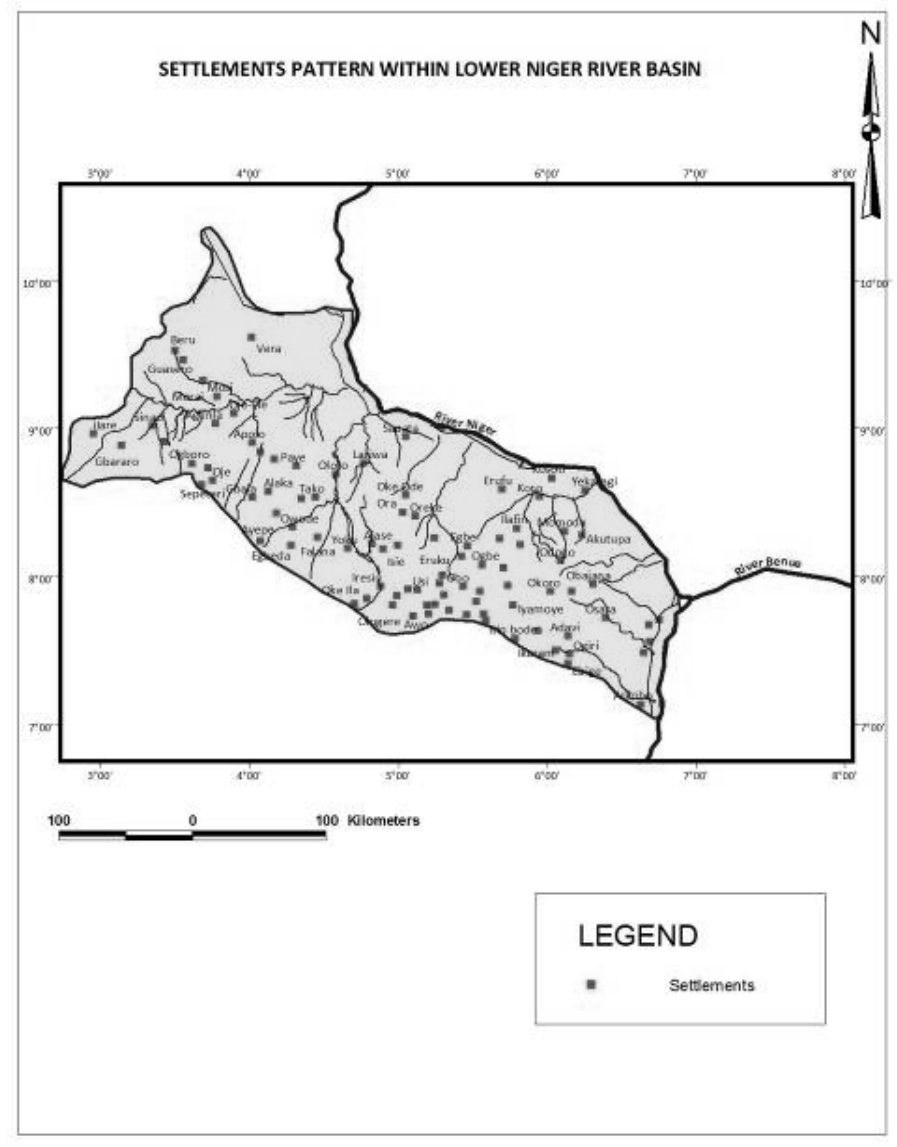

Figure 1a: Lower Niger River Basin 


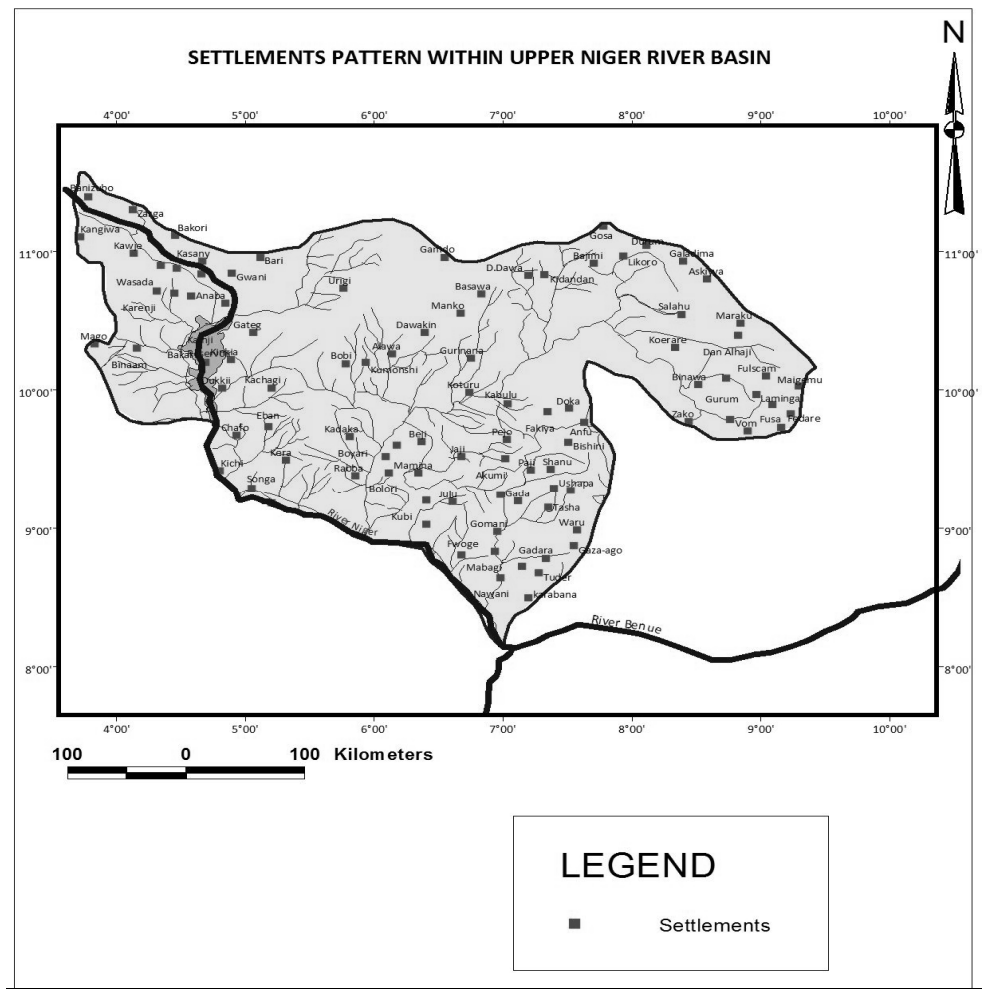

Figure 1b: Upper Niger River Basin

\section{Data Types and Processing}

The study relies on spatial data obtained from the Forestry Management Evaluation and Coordination Unit (FORMECU). Elevation data for the region was derived from the Shuttle Radar Topography Mission (STRM) data which was downloaded from their website. Digitized drainage pattern (figures $2 \mathrm{a}$ and $\mathrm{b}$ ), soil type map (figures $3 \mathrm{a}$ and $\mathrm{b}$ ) and land use map (figure $4 \mathrm{a} \& \mathrm{~b}$ ) alongside the Digital Elevation Model form the input into the flood risk analysis (Malczewski, 1996). These data are complemented by attribute data like rainfall and population data, obtained from Nigeria Meteorological Agency and Nigeria Communication Commission respectively. Spatial data from satellite images were georeferenced and existing digital data transformed to the WGS_1984 Projection System. This was done to allow for consistency and avoid representation errors that may arise from differing spatial extent of these data. The attribute most especially the population and rainfall (Samuel et al., 2014). 
Ethiopian Journal of Environmental Studies and Management Vol. 9 (Suppl. 1) 2016

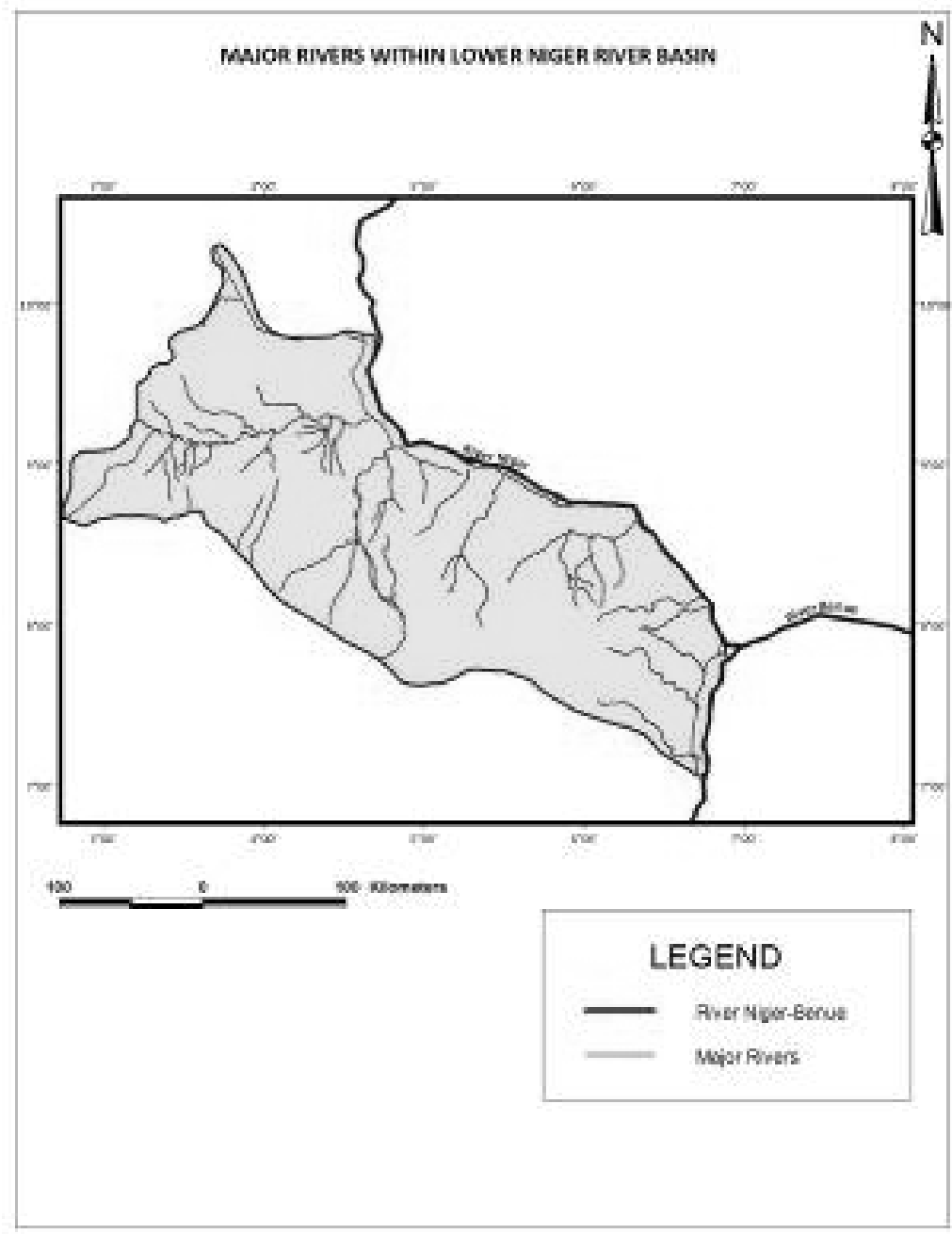

Figure 2a showing the drainage pattern within lower Niger river basin 
Flood Risk and Vulnerability Mapping of Settlements................ADEBAYO, H.0.

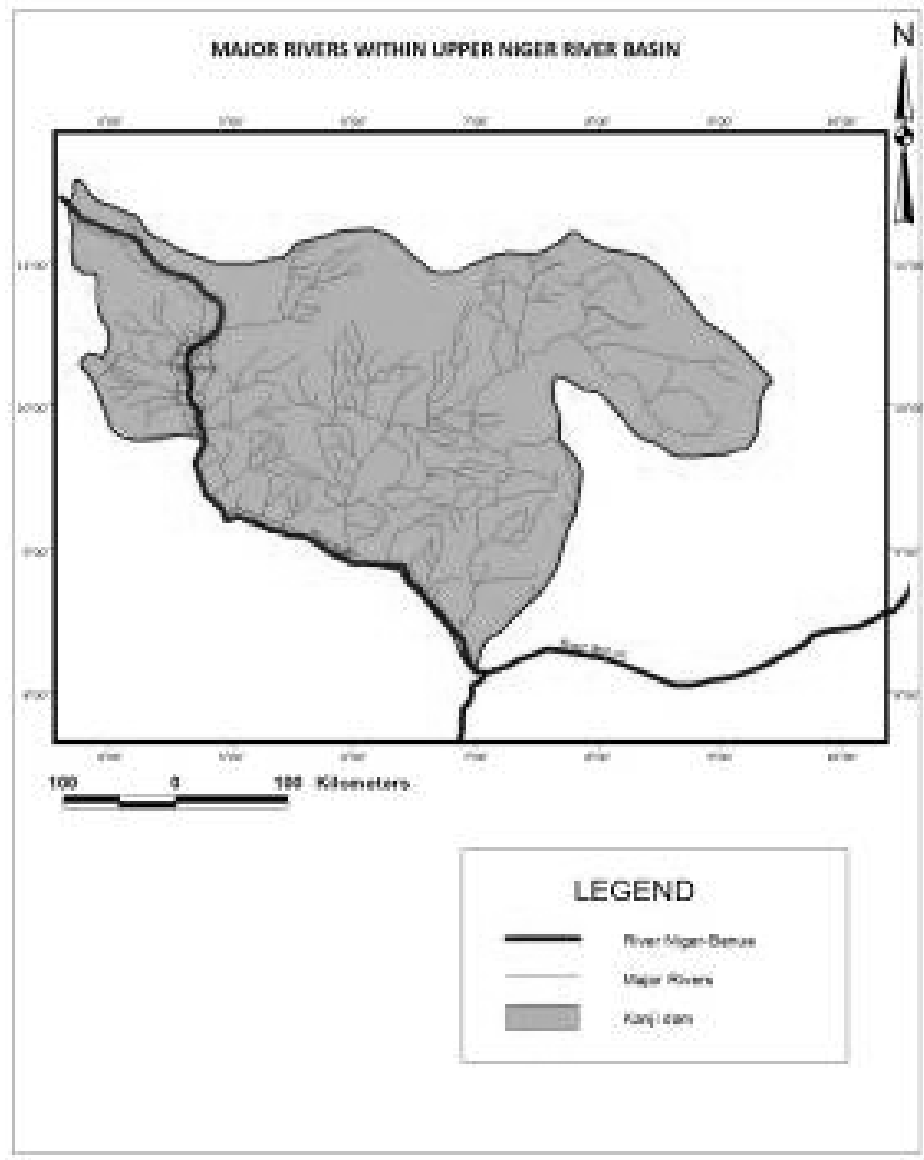

Figure $2 \mathrm{~b}$ showing the drainage pattern within upper Niger river basin 
Ethiopian Journal of Environmental Studies and Management Vol. 9 (Suppl. 1) 2016

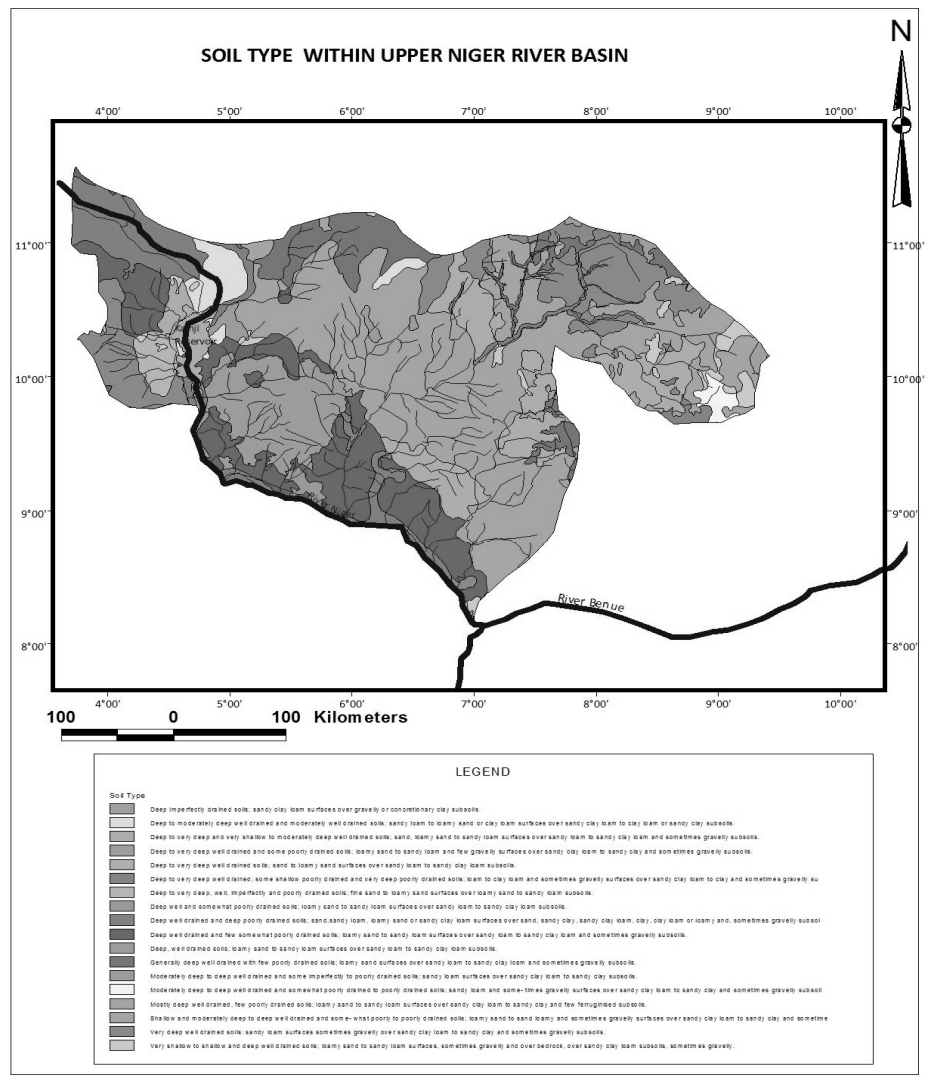

Figure 3a showing soil type within upper Niger river basin 
Flood Risk and Vulnerability Mapping of Settlements...............ADEBAYO, H.O.

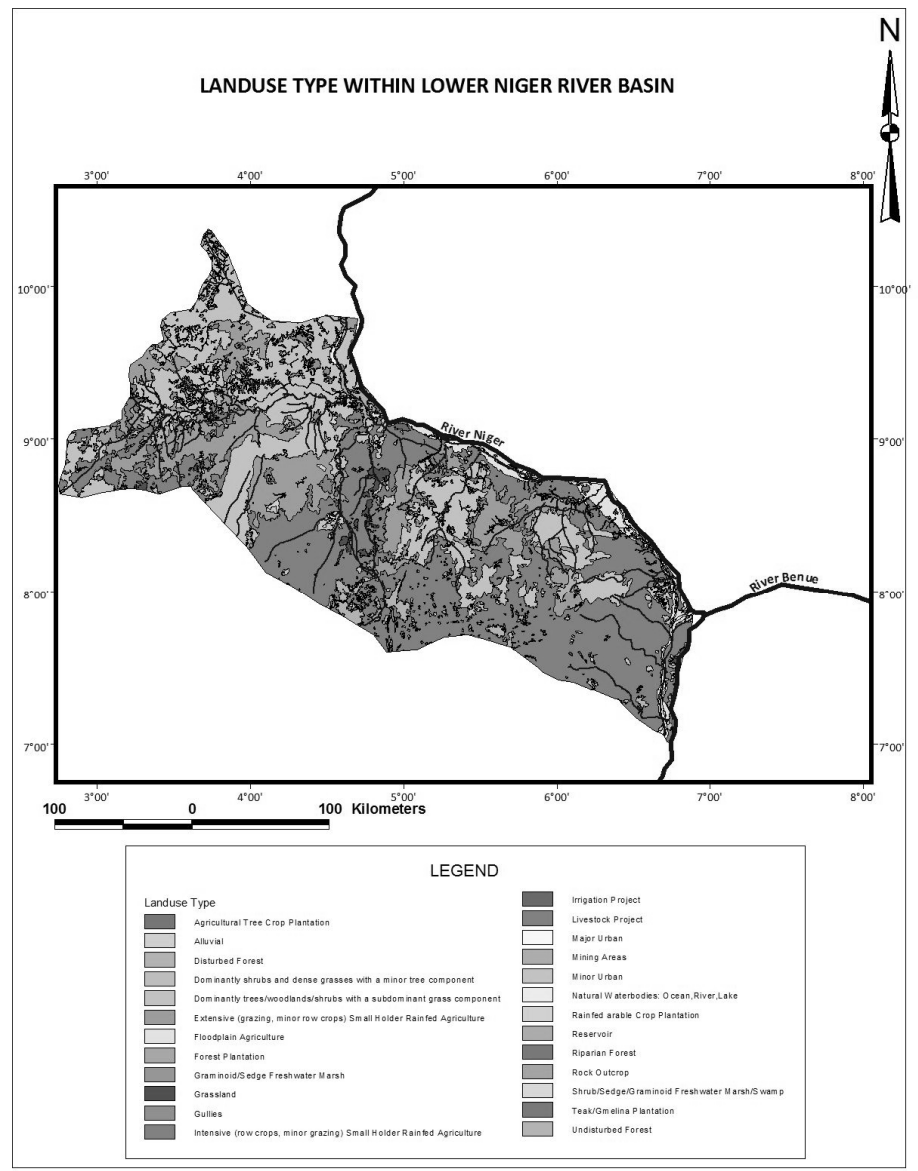

Figure 4 a showing landuse pattern within lower Niger river basin 


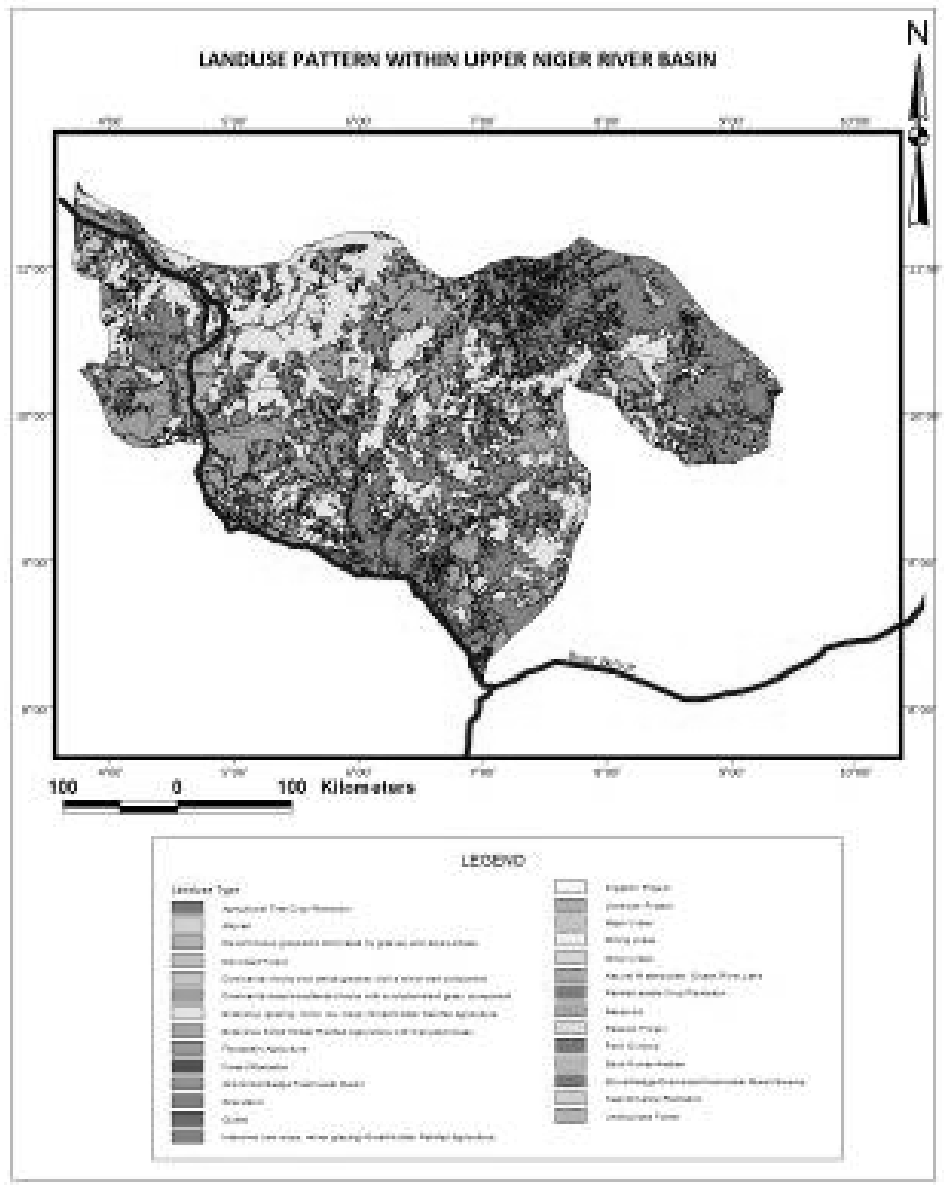

Figure $4 \mathrm{~b}$ showing landuse pattern within upper Niger river basin

ArcGIS 10.0 was used as professional GIS package, for the purpose of manipulating and processing data within a GIS environment. All the spatial data created in different layers are converted into compatible GIS format, and then the attributes tables created for each particular layer by using ArcGIS. Multi criteria analysis is applied in producing and combining spatial data describing the selected causing factors. The map layers were overlay using the method of Boolean overlay. All criteria are combined by logical operators such as intersection and union.

\section{Results and Discussion}

The data analysis for this study was essentially carried out within GIS framework, using ESRI's ArcGIS $10.0^{\mathrm{TM}}$. Three major variables were used to determine the risk exposure to flooding in the study area. They were combined by logical operations such as intersection and union in the Boolean approach. Each of the three variables was categorized into three major categories-high, medium and low risk factors using the ranking method (Saaty, 1980).In ranking method; every criterion under consideration is ranked in the order of the decision maker's preference. 
In generating criterion values for each evaluation unit, each of the selected factors for this study was weighted according to the estimated significance for causing flooding. The inverse type of ranking was adopted (Saaty, 1980). The study area is for the most part a lowland area made up of flood plain of major rivers. This informed the choice of the decision variables for delineating the area into high, medium and low flood risk areas. Since the rainfall regime is essentially the same for most parts of the study area, it was excluded from the decision variables. Generally, areas with height less than 180metres were designated as high risk areas; areas with height between 180.1 and 500metres were described as medium or moderate risk areas while areas above 500metres are designated as low risk areas (see figures $5 \mathrm{a}$ and $\mathrm{b}$ below).

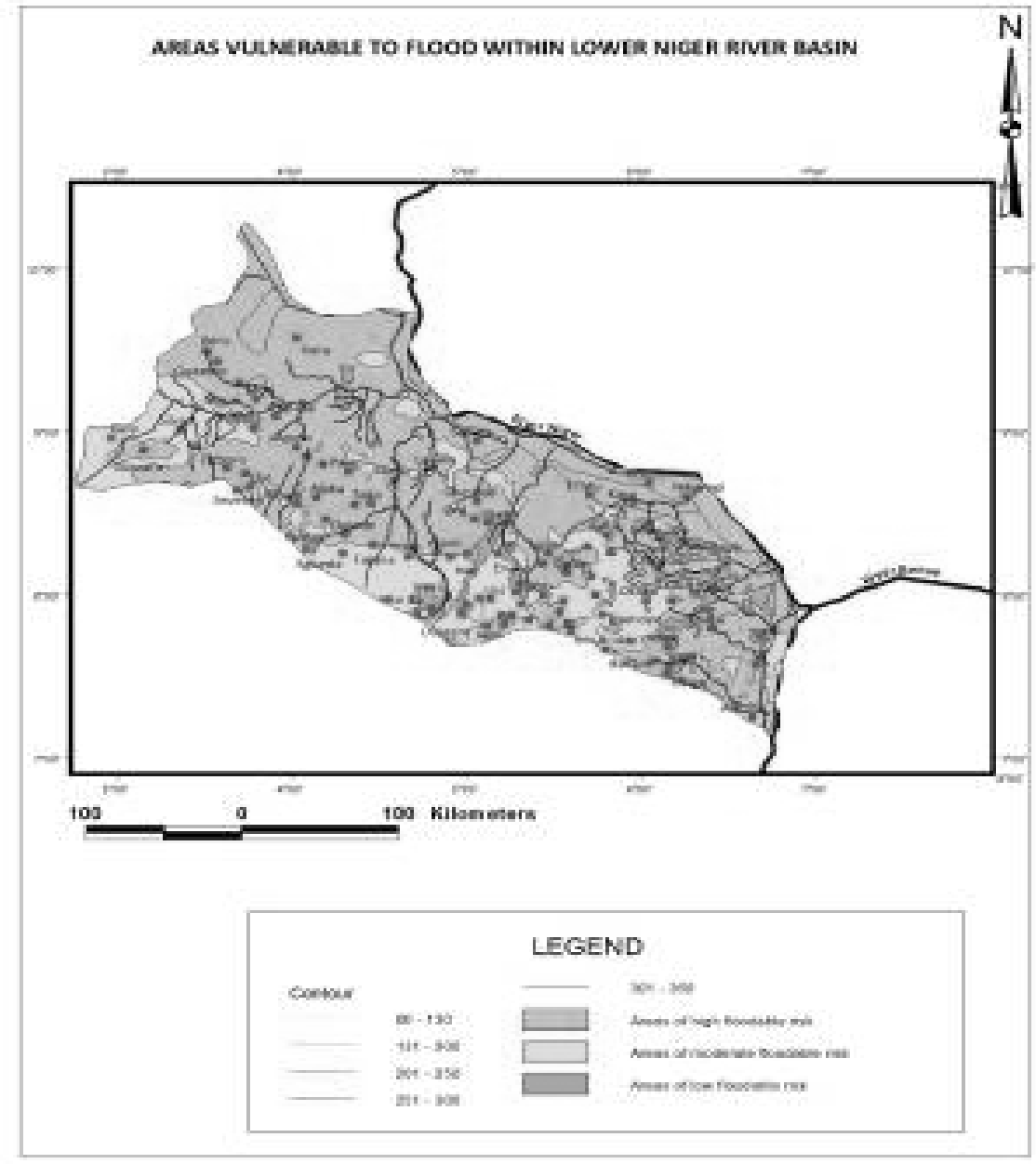

Figure 5a showing areas vulnerable to flood within Lower Niger River basin 


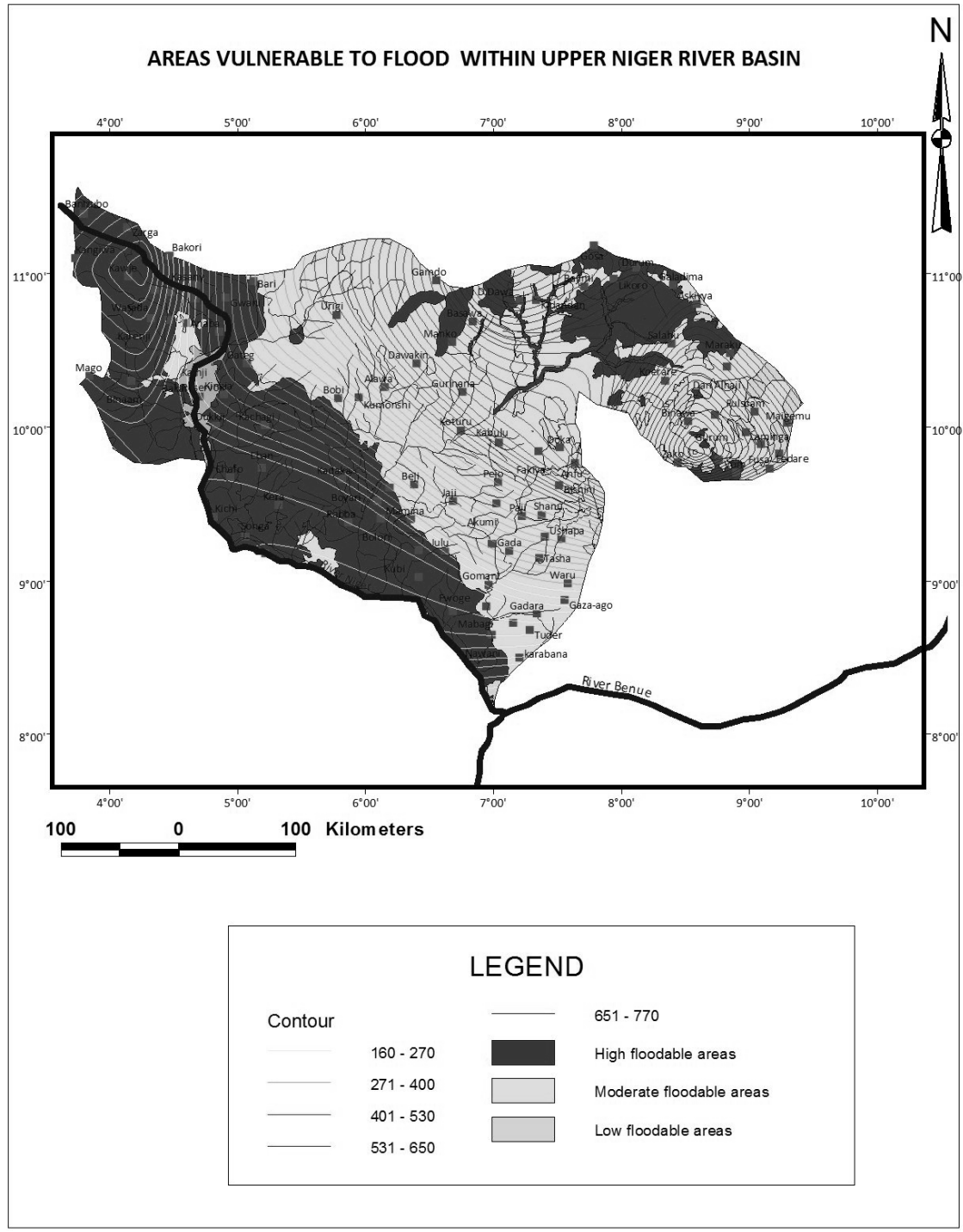

Figure $5 \mathrm{~b}$ showing areas vulnerable to flood within upper Niger River basin

Proximity to river channels is an important variable in this study. Distance from rivers and their tributaries were reckoned at $0.5,1.0$ and $1.5 \mathrm{~km}$, with areas within $0.5 \mathrm{~km}$ of river channels were categorized as high risk areas; areas within $0.5-1.0 \mathrm{~km}$ as medium risk areas and areas located at over $1.0 \mathrm{~km}$ to the river channels were described as low risk areas (figures 6a and $\mathrm{b}$ below). 
Flood Risk and Vulnerability Mapping of Settlements................ADEBAYO, H.O.

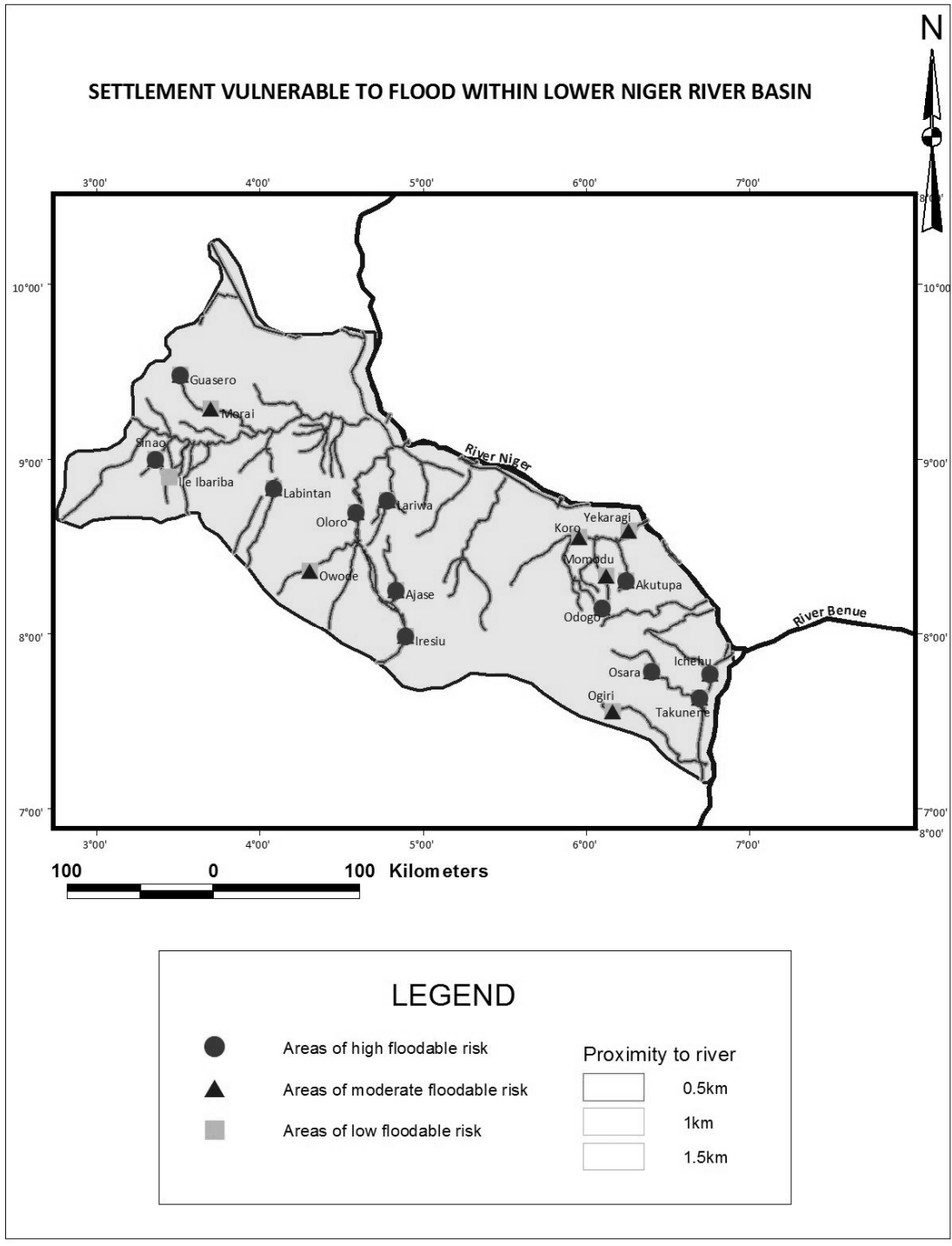

Figure 6a showing the proximty of settlements to drainage channels 


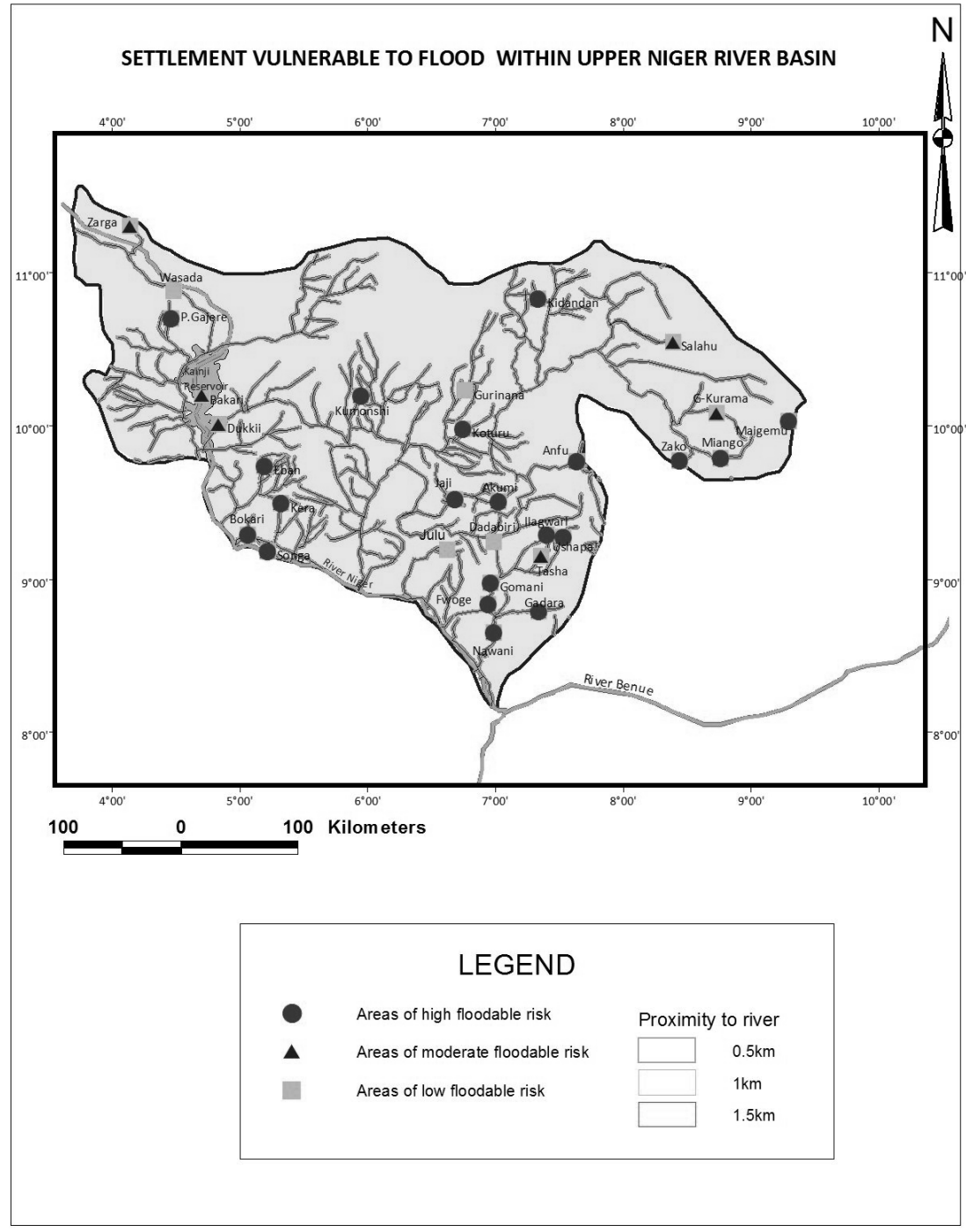

Figure $6 \mathrm{~b}$ showing the proximty of settlements to drainage channels

\section{Conclusion and Recommendations}

This study has attempted an assessment of flood risk and vulnerability mapping of settlements within Upper and Lower Niger River Basins. The study reveals that over 1,000 settlemnts harbouring over 15 million people are at grave risk of flooding. It is therefore imperative the policies aimed at mitigating the effect of flooding be strictly implemented in order to forestall losses in human lives and material possession.

\section{References}

ActionAid 2006. Climate change, urban flooding and the rights of the urban poor in Africa, key finding from 50 African cities, A report by ActionAid, ActionAid International.

Adebayo, O.H. (2014). GIS Based Model for Identifying Flood Vulnerable 
Areas in Ogun-Osun River Basin, Nigeria. Journal of Engineering and Environmental Studies, 5(1): 57-59.

Adedeji, O.H. Odufuwa, B.O. and Adebayo, O.H. (2012). Building Capabilities for Flood Disaster and Hazard Preparedness and Risk Reduction in Nigeria: Need for Spatial Planning and Land Management. Journal of Sustainable Development in Africa. 14(1): 45-58.

Aina, Tade Akin. (1995). Metropolitan Lagos: population growth and spatial expansion; city study. Background paper for the Global Report on Human Settlements, 31 pages.

Malczewski, J. (1996). A GIS-based approach to multiple criteria group decision making. International Journal of Geographical Information System, 10(8): 955977.

McCall, M.K. (2008). Participatory Mapping and Participatory GIS (PGIS) for CRA, Community DRR and Hazard Assessment. Available at

http://www.proventionconsortium.o rg/?pageid=48\#action (Accessed on December 12 2013).

Okosun, A.E., Ndukwu, R.I. and Chiemelu, N.E. (2009). Urban Growth Management of Nigerian Cities: A GIS Approach. Journal of Environmental Management and Safety. 1 (1): 165-179

Ologunrisa, E. (1999). Flood hazard perception and adjustment in Ondo, Southwestern Nigeria, Journal of Nigeria Affairs, 4:172-193.

Saaty, T.L. (1980). The Analytic Hierarchy Process, New York; McGraw $\mathrm{H}$

Samuel, K.J. Ayeni, B. Adebayo, O.H. and Adagbasa, E.G. (2014). A Geospatial Analysis of Flood Risks and Vulnerability in OgunOsun River Basin, Nigeria. M. Singh (eds). Landscape of Ecology and Water Management: Proceedings of IGU Rohtak Conference, Vol.2, Advances in Geographical and Environmental Sciences, DOI 10.1007/978-4-43154871-3_22 Springer Japan.

UN-Water. 2011. Cities coping with water uncertainties. Media Brief, UN-Water Decade Programme on Advocacy and Communication. 